\title{
Metodologia para avaliação da sustentabilidade de habitações de interesse social com foco no projeto
}

\author{
Methodology for evaluating the sustainability of social \\ interest houses with focus on design
}

\begin{abstract}
Michele Tereza Marques Carvalho Rosa Maria Sposto

Michele Tereza Marques Departamento de Engenharialho Ambiental, Faculdade de Engenharia

Universidade de Brasília Campus Universitário Darcy Ribeiro Brasília - DF - Brasil CEP 70919-900 Tel.: (61) 31071010

E-mail: micheletereza@unb.br

Rosa Maria Sposto Departamento de Engenharia Civil e Ambiental, Faculdade de Engenharia

Universidade de Brasília Tel.: (61)31070993 E-mail: rmsposto@unb.br

Recebido em 07/07/11 Aceito em 04/02/12

\section{Resumo}

$\mathbf{N}$

este trabalho é proposta uma metodologia para análise da sustentabilidade de projetos de habitações de interesse social, denominada MASP-HIS. A principal motivação para seu desenvolvimento foi a necessidade de estabelecimento de indicadores de sustentabilidade para esses tipos de edificações, considerando-se ações orientadas ao desenvolvimento mais sustentável de sua produção. Para a construção da metodologia foram elaborados critérios para a verificação dos requisitos de sustentabilidade de projeto levando-se em consideração os aspectos ambiental, sociocultural e econômico. Essa metodologia pode ser utilizada para a identificação e solução de pontos críticos de projeto, quando são analisados seus índices de sustentabilidade parciais, e para o mapeamento da sustentabilidade de projeto na localidade de aplicação; além disso, também se aplica na verificação da evolução do índice de sustentabilidade ao longo do tempo. A metodologia foi aplicada em dois empreendimentos de habitações de interesse social, localizados na região Centro-Oeste do Brasil. Os resultados oferecem algumas evidências da sua adequabilidade.

Palavras-chave: Sustentabilidade. Habitação de interesse social. Projetos. Metodologia.

\section{Abstract}

This paper presents a methodology called MASP-HIS, to be used in the analysis of the sustainability of social housing designs. The main motivation for this study was the need to establish sustainability indices for this type of construction, considering actions aimed at a more sustainable development of their production. A set of criteria was established to verify design sustainability requirements, taking into account environmental, socio-cultural and economic aspects. This methodology can be used to identify and solve critical elements of a design when the partial indices of sustainability are analyzed, and to map the design's sustainability at the site of its application. It is also applied in the verification of the evolution of the sustainability index over time. The methodology has been applied in two social housing projects located in the Midwest of Brazil. The results provide some evidences of the adequacy of the methodology.

Keywords: Sustainability. Social housing. Projects. Methodology.
\end{abstract}




\section{Introdução}

Apesar de uma conscientização tardia, a construção civil vem adotando posturas mais proativas em relação ao meio ambiente e à sustentabilidade. Agopyan et al. (1998) apontam como sendo do início da década de 1990 o surgimento das primeiras medidas consistentes no Brasil, com estudos mais sistemáticos e resultados mensuráveis sobre reciclagem, redução de perdas e de energia na construção civil.

Em relação à legislação, observam-se alguns avanços na busca de maior eficiência no processo de produção de edificações, tais como a Resolução 307/2002 do Conama, a Lei de Eficiência Energética de 2001 (BRASIL, 2001) e o Programa Nacional de Conservação de Energia Elétrica (Procel) (BRASIL, 2001), também aplicado à etiquetagem de edificações. A Resolução do Conama estabelece responsabilidades para o resíduo da construção civil, o que pode vir a gerar uma melhor gestão e, portanto, maior eficiência no uso de materiais nos canteiros. O Procel, que estabelece níveis mínimos de eficiência energética, contribui para a racionalização do uso de energia.

Por fim, em termos de produtos, tem-se observado a entrada no mercado de inovações denominadas mais sustentáveis, tais como vasos sanitários com redução de vazão, torneiras com sensores, sistemas de geração de energia alternativa e outros.

Entretanto, para que o Brasil desenvolva-se de forma sustentável, é preciso reduzir o déficit de habitação para as populações de baixa renda, o que hoje é um dos maiores problemas sociais. Além da redução do déficit, porém, há de se considerar a qualidade dessas habitações, considerando-se a sustentabilidade, entre outras exigências, definida pela durabilidade, manutenabilidade e adequação ambiental, conforme a NBR 15575 (ABNT, 2010). Também, na produção dessas habitações, há a necessidade de integrarem-se as diversas dimensões da sustentabilidade, quais sejam: social, econômica, ecológica, espacial e cultural.

Segundo Choguill (2007), para que as políticas de habitação resolvam o problema habitacional com sustentabilidade, isto é, para que sejam viáveis economicamente, socialmente aceitas e com técnicas praticáveis e ambientalmente compatíveis, são necessários:

(a) participação da comunidade em todas as etapas, para a busca de redução dos custos, satisfação de todos os envolvidos e garantia de qualidade;

(b) materiais de boa qualidade e custos acessíveis, com respeito à preservação ambiental; (c) padrões de desempenho mínimos, tais como os relacionados a saúde, higiene, fogo,

flexibilidade e segurança;

(d) financiamentos com maiores prazos; e

(e) garantia de disponibilidade de terra adequada à construção por meio da valorização social do solo.

Este trabalho tem por objetivo descrever uma metodologia desenvolvida para avaliar projetos de habitações de interesse social, considerando-se os aspectos ambientais, socioculturais e econômicos, intitulada "Metodologia para Análise de Sustentabilidade de Projetos de Habitações de Interesse Social - MASP-HIS”.

Essa metodologia analisa as características que podem conferir sustentabilidade aos projetos e apresenta resultados na forma de índices de sustentabilidade, tanto parciais, para cada um dos aspectos citados, como de projeto, englobando todos os aspectos em conjunto.

Em virtude da grande quantidade de dados necessários para a verificação da sustentabilidade de projeto e com a finalidade de viabilizar os cálculos dos índices de sustentabilidade de forma rápida e segura, desenvolveu-se uma ferramenta denominada PROMASP-HIS. Essa ferramenta foi construída na linguagem Visual Basic, com a utilização de interface gráfica e de entrada e saída de dados do software Microsoft Excel ${ }^{\mathrm{TM}}$, que também se presta à execução dos cálculos e das operações lógicas necessárias. Para testar sua exequibilidade do ponto de vista da compreensão de seu conteúdo, procedeu-se a sua aplicação em dois projetos de habitações desenvolvidos na região metropolitana de Goiânia, GO.

\section{Interfaces entre projetos, sustentabilidade e métodos de avaliação de sustentabilidade}

O projeto é um dos elementos fundamentais do processo de produção no setor da construção. É na fase de projeto que o produto é concebido e os materiais e as técnicas construtivas são especificados. É o elemento indutor da racionalização da construção, da qualidade do produto final e de sua sustentabilidade.

Segundo o U. S. Green Building Council, o conceito de green design refere-se a práticas de projeto e construção que significativamente reduzem ou eliminam o impacto negativo dos edifícios e dos ocupantes no ambiente, em cinco grandes áreas (UNITED..., 2011): 
(a) planejamento sustentável local;

(b) proteção e uso eficiente dos recursos hídricos;

(c) eficiência energética;

(d) conservação de recursos e materiais; e

(e) qualidade do ar interno.

Para Cheung e Cheng (2008), os requisitos para projetos sustentáveis em Hong Kong são:

(a) sustentabilidade social:

- conectividade;

- serviços;

- vizinhança e contexto; e

- cultura e patrimônio da comunidade.

(b) sustentabilidade econômica:

- qualidade;

- flexibilidade para mudança;

- reutilização das estruturas existentes; e

- estratégia de manutenção eficiente.

(c) sustentabilidade ambiental:

- saúde do ambiente;

- ventilação natural;

- microclima;

- conservação de energia;

- água; e

- conforto ambiental.

A elaboração de um projeto é um processo complexo, que exige um desempenho cada vez melhor. Além da complexidade, há potenciais deficiências no processo, como, por exemplo, dificuldade de integração entre as atividades de projeto e execução, falta ou ineficácia da gestão de qualidade e da gestão ambiental, ausência de integração entre os agentes envolvidos e carência de projetistas com especialização contínua. Observa-se também nesse campo a necessidade de mudanças de paradigmas, por meio de um esforço interativo de todos os envolvidos com pesquisa, planejamento, controle e uso de métodos sistemáticos.

Visando facilitar a integração de considerações de sustentabilidade na tomada de decisões para a viabilização de novos empreendimentos, Kaatz (2006) afirmam que a aplicação de metodologias e sistemas de avaliação da sustentabilidade de edificações representa um dos meios de implantação da Agenda 21, uma vez que as avaliações possibilitam decisões mais conscientes dos impactos e das ações de mitigação.
Cole et al. (2005) apontaram alguns avanços proporcionados pelo uso de métodos de avaliação, tais como:

(a) prática de projeto de edificações ecológicas, na medida em que fornecem uma lista de questões em uma estrutura com prioridades explícitas para serem inseridas no rol de questões normalmente consideradas no processo de tomada de decisão;

(b) possibilidade de descrição abrangente do desempenho ambiental de uma edificação, mesmo por meio de critérios prescritivos; e

(c) possibilidade de reformulação do processo de projeto, tendo em vista que a inclusão de critérios ambientais requer maior integração e trabalho multidisciplinar.

De acordo com Silva (2003), Sperb (2000) e Oliveira (2005), uma vez apresentada e justificada a necessidade de desenvolverem-se sistemas de avaliação da sustentabilidade de edificações no contexto brasileiro, deve-se levar em conta as limitações existentes em termos de dispersão de estudos, ausência de dados confiáveis e conhecimento e interesse sobre questões ambientais por conta dos agentes envolvidos na tomada de decisão.

Observa-se, no contexto aqui estudado, que o desenvolvimento de metodologias e ferramentas capazes de avaliar a sustentabilidade, ora certificando, ora apoiando medidas que levem a construções mais sustentáveis, está em desenvolvimento dinâmico e acelerado em várias partes do mundo, como nos Estados Unidos, Inglaterra, Canadá, França, Portugal, Japão, África do Sul e Brasil, entre outros países, forçando mudanças rápidas do segmento no que diz respeito aos impactos ambientais, sociais e econômicos gerados.

Após a revisão da literatura acerca do tema realizada neste trabalho, destacam-se alguns sistemas de avaliação ambiental de edifícios tais como: BREEAM (Building Research Establishment Environmental Assessment Method) (BUILDING..., 2007), GBTool (Green Building Challenge) (LARSSON, 2005), LEED (Leadership in Energy and Environmental Design) (UNITED..., 2011), CASBEE (Comprehensive Assessment System for Building Environmental Efficiency) (IWAMURA, 2005), HK-BEAM (Hong Kong Building Environmental Assessment Method) (LAM, 2008), HQE (NF Bâtiments Tertiaires: Démarche HQE® Bureau et Einseignement) (BUREAU/ENSEIGNEMENT, 2008), MARS (Building Sustainability Assessment Tool), Lidera (Sustainable Assessment System) (BRAGANÇA; MATHEUS, 2008) e SBAT 
(Sustainable Building Assessment Tool) (GIBBERD, 2008). No Brasil podem ser citados os trabalhos de Silva (2003) e Fossati (2008). Além disso, no mercado brasileiro de produção de edificações têm sido utilizados o AQUA (AQUA, 2007) (adaptado do HQE) e o LEED.

Observa-se que as metodologias ou sistemas citados avaliam em sua maior parte apenas os aspectos ambientais, deixando como lacuna os aspectos sociais e econômicos. Visando preencher essa lacuna, foi proposto este trabalho, que considera aspectos ambientais, econômicos e sociais, tomando-se como base teórica as metodologias e sistemas mencionados anteriormente.

Buscou-se, então, desenvolver a metodologia MASP-HIS e sua ferramenta computacional, com base em indicadores de sustentabilidade, a partir dos critérios estabelecidos pela norma ISO/TS 21929-1 (ISO, 2006), em conformidade com os estudos dos sistemas de avaliação descritos anteriormente, mas com enfoque nos aspectos socioculturais e econômicos, além dos ambientais.

Essa norma ISO define indicadores como elementos que possibilitam extrair uma informação simplificada com base em fenômenos complexos, tais como impactos ambientais, sociais e econômicos. Tais indicadores têm como principais funções a quantificação, a simplificação e a comunicação.

Dessa forma, a mesma norma define uma estrutura de indicadores de sustentabilidade de edificações baseada na premissa de que a construção sustentável deve atingir o desempenho das técnicas de construção com o mínimo de impacto ambiental. Ao mesmo tempo, incentiva a construção sustentável considerando a integração dos aspectos econômicos, sociais e culturais nos níveis local, regional e global.

Segundo a Organization for Economic Cooperation and Development (ORGANIZATION..., 1993), um indicador deve estar diretamente relacionado a um valor. Por outro lado, conforme apontado por Silva (2007), os indicadores de sustentabilidade surgiram primeiro na esfera das nações, em resposta à Agenda 21. Vários níveis de indicadores foram estabelecidos: indicadores nacionais (OECD, ONU, World Bank, UN CSD United Nations Comission for Sustainable Development ${ }^{1}$ ), indicadores setoriais de

\footnotetext{
${ }^{1} \mathrm{Na}$ esfera das nações CSD - Theme Indicator Framework organiza os indicadores em quatro dimensões: aspectos sociais, ambientais, econômicos e institucionais.
}

sustentabilidade da construção civil (CIRIA $^{2}$, CRISP ${ }^{3}$ ), indicadores de sustentabilidade organizacional - empresas de projetos e construção (Global Reporting Iniciative Guidelines) - $\mathrm{e}$ indicadores de edifícios e projetos (LEED, BREEAM, GBC). É importante observar que os indicadores definidos em esferas de avaliação mais restritas devem alinhar-se aos indicadores e às metas de desenvolvimento sustentável definidas nos âmbitos nacional e mundial.

Segundo Huovila (2008), os indicadores são usados para medir o desempenho e monitorar tendências, e devem possuir as seguintes características:

(a) relevância: isto é, clara ligação com o desempenho da meta;

(b) objetividade: com base em informações confiáveis;

(c) acessibilidade: de dados confiáveis;

(d) legibilidade: que seja compreensível pela comunidade;

(e) mensurabilidade; e

(f) sensibilidade: para que seu uso seja confiável.

Para Wallbaum (2008), indicadores de sustentabilidade de edificações devem incluir os aspectos ambientais e econômicos bem como os aspectos sociais, isto é, eles têm de abranger todas as dimensões da sustentabilidade e do ciclo de vida da edificação; precisam ter rastreabilidade e transparência para garantir a precisão científica e a comunicação; devem atender às condições locais; e seus limites devem ser estabelecidos em razão da praticidade, e não à custa de certeza direcional.

A estrutura de categorias para a avaliação da sustentabilidade, tendo como base a norma europeia CEN TC 350, segundo Lützkendorf e Ilomäki (2007) e Desmyter e Huovila (2008), é estabelecida por categorias:

(a) categoria de impactos ambientais (Análise do Ciclo de Vida ACV - mudança do clima, destruição da camada de ozônio, acidificação e eutroficação da atmosfera e das águas);

(b) categoria de aspectos ambientais (depreciação de recursos não renováveis, uso de recursos, de energia e de água, disposição de resíduos);

\footnotetext{
2 CIRIA - Construction Industry Research and Information Association: indicadores de sustentabilidade para a indústria da construção do Reino Unido (CONSTRUCTION..., 2001).

${ }^{3}$ CRISP - Construction and City Related Sustainability Indicators: indicadores de sustentabilidade relacionados ao setor de construção (rede europeia) (CRISP..., 2001).
} 
(c) categoria conforto e saúde (conforto higrotérmico, qualidade do ar, condições de ventilação, confortos acústico e lumínico, qualidade da água potável); e

(d) categoria do custo do ciclo de vida (custos antes de construir, de manutenção, de operação e de desconstrução).

Observa-se, então, que os indicadores ambientais estão relacionados com os impactos que as edificações podem causar a elementos naturais, como clima, atmosfera, recursos hídricos e não renováveis, entre outros, bem como com a mitigação desses impactos a partir da reciclagem, da disposição correta de resíduos e do uso adequado dos recursos naturais.

Por outro lado, os indicadores econômicos indicam fluxos financeiros ligados à edificação. Dessa forma, a avaliação do impacto econômico dessas edificações pode ser baseada no custo do ciclo de vida, considerando os custos do investimento inicial (local, projeto, produção, construção), do uso (consumo de água e de energia e gerenciamento dos resíduos), da manutenção, da desconstrução, além da taxa de retorno e do rendimento gerado pela edificação e por seus serviços.

Os projetos de edificações podem beneficiar-se com o uso de avaliação dos custos do ciclo de vida no início da etapa de concepção, para que os resultados contribuam para apoiar as decisões tanto de investimento como de custos de operação (KRIGSVOLL, 2008).

Os indicadores sociais, no entanto, são usados para descrever como as edificações interagem em relação aos assuntos atinentes à sustentabilidade com a comunidade local ${ }^{4}$. Como aspectos sociais, a ISO/TS 21929-1 (ISO, 2006) sugere que os indicadores contemplem os seguintes temas:

(a) qualidade das construções como um lugar para viver e trabalhar;

(b) saúde e segurança dos usuários;

(c) barreira livre de utilização de edifícios;

(d) acesso aos serviços necessários pelos usuários de uma edificação;

(e) satisfação do usuário;

\footnotetext{
${ }^{4}$ Em nível comunitário sobre questões que podem ser relevantes estão as expansões urbanas misturadas à utilização das terras, ao acesso a serviços básicos, incluindo o transporte público, à disponibilidade de espaços verdes e abertos, à atratividade dos centros urbanos, ao desenvolvimento de áreas, à disponibilidade de habitação, à segregação social, à qualidade cultural e de proteção do patrimônio cultural, à segurança, ao ruído e à qualidade do ar (ISO, 2006).
}

(f) coesão social e participação dos usuários e de outras partes interessadas no processo de construção;

(g) qualidade arquitetônica das edificações; e proteção do patrimônio cultural.

Quanto aos temas sociais, não se pode deixar de citar os indicadores Ethos de Responsabilidade Social, referentes aos seguintes aspectos:

(a) valores, transparência e governança em compromissos éticos;

(b) valorização do público interno;

(c) gestão participativa; respeito ao indivíduo e trabalho decente; $\mathrm{e}$

(d) relação com os consumidores, clientes, fornecedores, comunidade e governo (ETHOS, 2011).

Os indicadores estabelecidos na metodologia proposta neste trabalho são considerados indicadores de desempenho, para ser utilizados no contexto da avaliação de projetos de habitações de interesse social. Possibilitam avaliação para fins de melhorias de projetos, estabelecem benchmarks e permitem comparações entre projetos individuais, apoiando as tomadas de decisão e o planejamento estratégico do setor com base na sustentabilidade no que se refere aos aspectos ambientais, socioculturais e econômicos.

\section{Metodologia para Análise de Sustentabilidade de Projetos de Habitações de Interesse Social - MASP-HIS}

A Metodologia para Análise de Sustentabilidade de Projetos de Habitações de Interesse Social MASP-HIS, apresentada neste trabalho, foi estruturada segundo a ordem hierárquica apresentada na Figura 1.

Os índices propostos para a avaliação de sustentabilidade de projetos (Figura 1) foram determinados a partir da verificação dos principais elementos que devem estar presentes no projeto, para que os requisitos de sustentabilidade sejam satisfeitos. A partir dessa verificação, procedeu-se à estruturação da metodologia, com base em perguntas relacionadas aos aspectos ambientais, socioculturais e econômicos, formuladas e reunidas em cinco grupos, conforme descritos a seguir. 


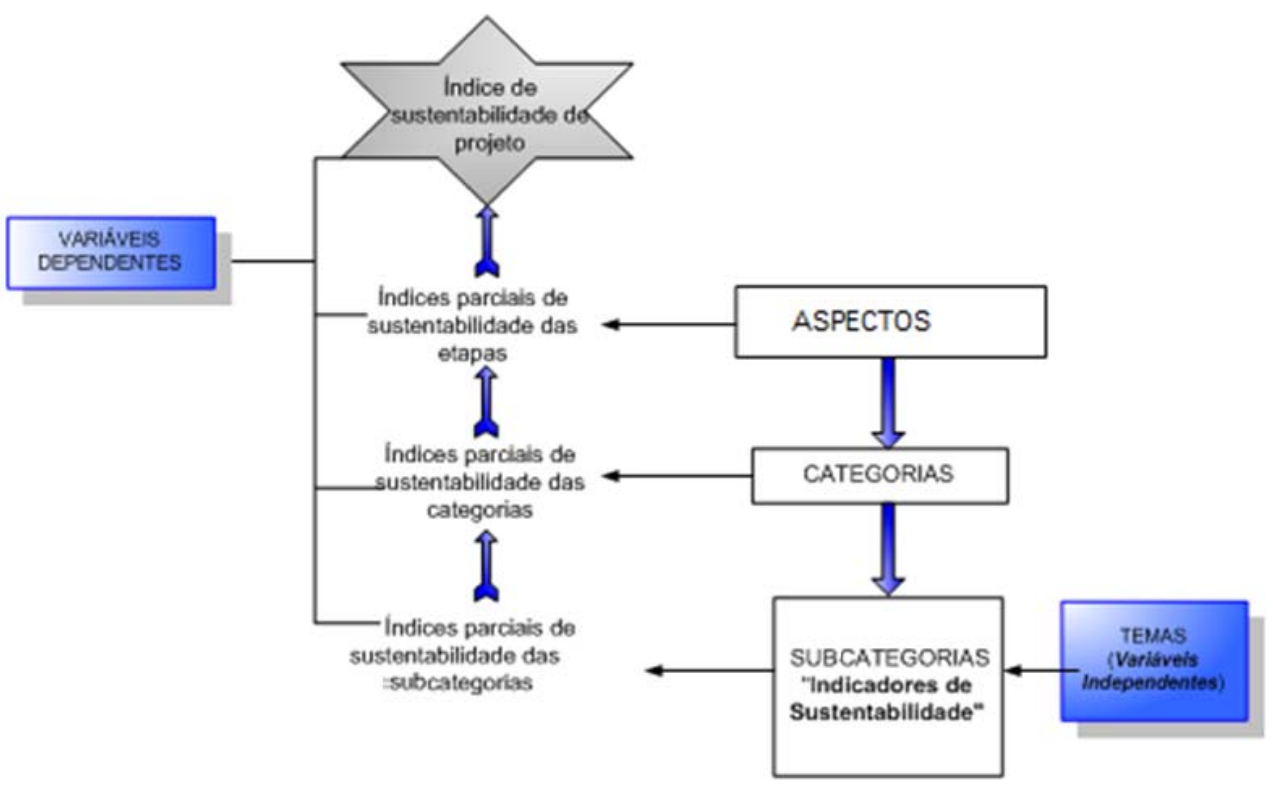

Figura 1 - Estrutura hierárquica do método MASP-HIS

Grupo 1 - Como podem ser medidos os aspectos ambientais, socioculturais e econômicos?

Grupo 2 - Quais são os elementos necessários para contemplar os aspectos ambientais, socioculturais e econômicos para a construção sustentável?

Grupo 3 - Esses elementos são aplicáveis em HIS?

Grupo 4 - Quais temas relacionados àqueles elementos são aplicáveis à fase de projeto?

Grupo 5 - Os temas aplicáveis à fase de projeto podem ser dispostos na forma de check list com resposta SIM ou NÃO?

Verificou-se, em resposta à pergunta do grupo 1, que os aspectos ambientais, socioculturais $\mathrm{e}$ econômicos podem ser medidos na forma de indicadores, de acordo com os critérios e requisitos apresentados na literatura pesquisada. Com isso, a ideia foi reunir esses critérios e requisitos em uma única metodologia e dividi-los em categorias.

As respostas às perguntas do grupo 2, aplicáveis em HIS (de acordo com as perguntas do grupo 3 ), foram reunidas em subcategorias para cada categoria definida, conforme apresentadas nas Figuras 2, 3 e 4, em seus respectivos aspectos ambientais, socioculturais e econômicos. As subcategorias são os indicadores de sustentabilidade da metodologia MASP-HIS.

A partir da pergunta do grupo 4, foram identificados temas aplicáveis à fase de projeto, dentro de cada indicador. Foram aproveitados os temas que, na forma de perguntas, podem ser dispostos como check list, com resposta SIM ou $\mathrm{NÃO}$, atendendo à pergunta do grupo 5 .
A partir desses temas, incluídos na ferramenta PROMASP-HIS, o profissional responsável pela análise da sustentabilidade do projeto de HIS em análise deve informar se o projeto contempla ou não os temas previstos para cada um dos indicadores ambientais. Ele também pode verificar que o tema não se aplica ao projeto em questão e, assim, excluí-lo automaticamente dos cálculos.

As respostas positivas e/ou negativas dos temas, em análises de projetos específicos, refletem no valor dos indicadores e dos sucessivos índices parciais e de projeto, conforme a hierarquia apresentada na Figura 1. As respostas positivas, no entanto, elevam os valores dos indicadores e dos índices, e indicam maior nível de sustentabilidade. As fórmulas para a obtenção desses valores estão apresentadas nos itens subsequentes.

As respostas aos temas são as variáveis independentes e configuram os dados de entrada da metodologia MASP-HIS. Os índices de sustentabilidade, por sua vez, são as variáveis dependentes.

\section{Aspectos ambientais para a análise dos projetos completos}

Os aspectos ambientais para a análise dos projetos completos foram divididos em três categorias (A, B e C), as quais, por sua vez, foram divididas em subcategorias, conforme pode ser observado na Figura 2. As subcategorias são os indicadores ambientais para a análise dos projetos completos das edificações. 


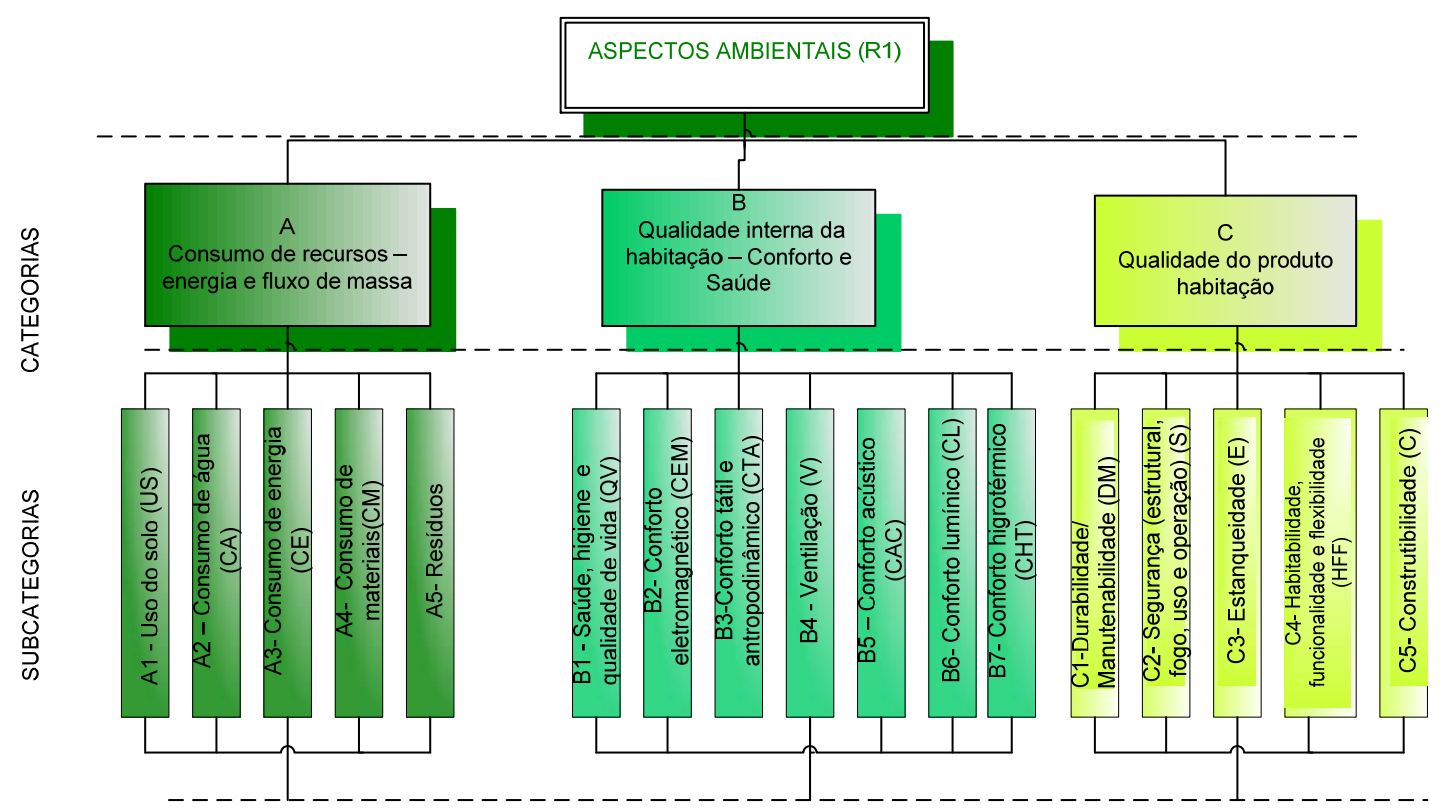

Figura 2 - Aspectos ambientais para a análise dos projetos completos das edificações

\section{Indicadores e índices ambientais para a análise dos projetos completos das edificações}

Os indicadores ambientais (subcategorias dos aspectos ambientais) para a análise dos projetos completos das edificações foram estabelecidos conforme o Quadro 1.

Como os indicadores devem ter, por definição, seus índices calculados com fórmulas matemáticas simples, de modo a possibilitar um fácil e rápido entendimento, esses índices foram estabelecidos pela relação $Q S / Q T$, na qual $Q S$ é a soma das respostas SIM e $Q T$, a soma das respostas SIM e NÃO, para cada um dos temas.

É ilustrada nas Figuras 3 e 4 a estrutura da metodologia, por meio da ferramenta PROMASPHIS, com o intuito de apresentar exemplos dos temas propostos para os aspectos ambientais.

Ainda, foram definidos os valores máximos e mínimos para os índices, sendo o valor máximo 100. Para o projeto ser considerado sustentável, deve-se alcançar no mínimo 50.

Os índices parciais de sustentabilidade ambientais das subcategorias são os valores dos próprios indicadores, obtidos com as equações apresentadas no Quadro 1. Os índices parciais de sustentabilidade ambientais das categorias A, B e C, por sua vez, são obtidos, respectivamente, pelas Equações 1, 2 e 3.

$$
\begin{array}{ll}
A=\frac{U S+C A+C E+C M+R}{5} 100 & \text { Eq. } 1 \\
B=\frac{Q V+C E M+C T A+V+C A+C L+C H T}{7} 100 & \text { Eq. } 2 \\
C=\frac{D M+S+E+H F F+C}{5} 100 & \text { Eq. } 3
\end{array}
$$

Por conseguinte, o índice parcial de sustentabilidade do aspecto ambiental (R1) é calculado pela Equação 4.

$A A=\frac{A+B+C}{3}$

Eq. 4

Nesta metodologia todas as categorias e subcategorias são tratadas com o mesmo grau de importância. Observa-se que há necessidade de aprimorar-se essa questão em trabalhos futuros, analisando a viabilidade de estabelecimento de diferentes pesos para cada uma delas. 
Quadro 1 - Indicadores ambientais para a análise dos projetos completos das edificações, equação e quantidade de perguntas (temas) para cada indicador

\begin{tabular}{|c|c|c|c|}
\hline Categoria & $\begin{array}{c}\text { Subcategoria (indicador de sustentabilidade } \\
\text { ambiental) }\end{array}$ & Equações & Qtde de temas \\
\hline \multirow{5}{*}{$\begin{array}{c}(\mathrm{A}) \\
\text { Consumo } \\
\text { de } \\
\text { Recursos, } \\
\text { Energia e } \\
\text { Fluxo de } \\
\text { Massa }\end{array}$} & Uso do solo (US) & $U S=Q S / Q T$ & 26 \\
\hline & Consumo de água (CA) & $C A=Q S / Q T$ & 9 \\
\hline & Consumo de energia (CE) & $C E=Q S / Q T$ & 6 \\
\hline & Consumo de materiais (CM) & $C M=Q S / Q T$ & 11 \\
\hline & Resíduos (R) & $R=Q S / Q T$ & 11 \\
\hline \multirow{7}{*}{\begin{tabular}{l}
\multicolumn{1}{c}{ (B) } \\
Qualidade \\
Interna da \\
Habitação \\
- Conforto \\
e Saúde
\end{tabular}} & Saúde, higiene e qualidade de vida (QV) & $Q V=Q S / Q T$ & 9 \\
\hline & Conforto eletromagnético (CEM) & $C E M=Q S / Q T$ & 2 \\
\hline & Conforto tátil e antropodinâmico (CTA) & $C T A=Q S / Q T$ & 3 \\
\hline & Ventilação (V) & $V=Q S / Q T$ & 13 \\
\hline & Conforto acústico (CA) & $C A=Q S / Q T$ & 7 \\
\hline & Conforto lumínico (CL) & $C L=Q S / Q T$ & 15 \\
\hline & Conforto higrotérmico (CHT) & $C H T=Q S / Q T$ & 7 \\
\hline \multirow{5}{*}{$\begin{array}{c}\text { (C) } \\
\text { Qualidade } \\
\text { do } \\
\text { Produto/ } \\
\text { Habitação }\end{array}$} & Durabilidade (DM) & $D M=Q S / Q T$ & 9 \\
\hline & Segurança (estrutural, fogo, uso e operação) (S) & $S=Q S / Q T$ & 25 \\
\hline & Estanqueidade (E) & $E=Q S / Q T$ & 11 \\
\hline & Habitabilidade, funcionalidade e flexibilidade (HFF) & $H F F=Q S / Q T$ & 8 \\
\hline & Construtibilidade (C) & $C=Q S / Q T$ & 10 \\
\hline
\end{tabular}

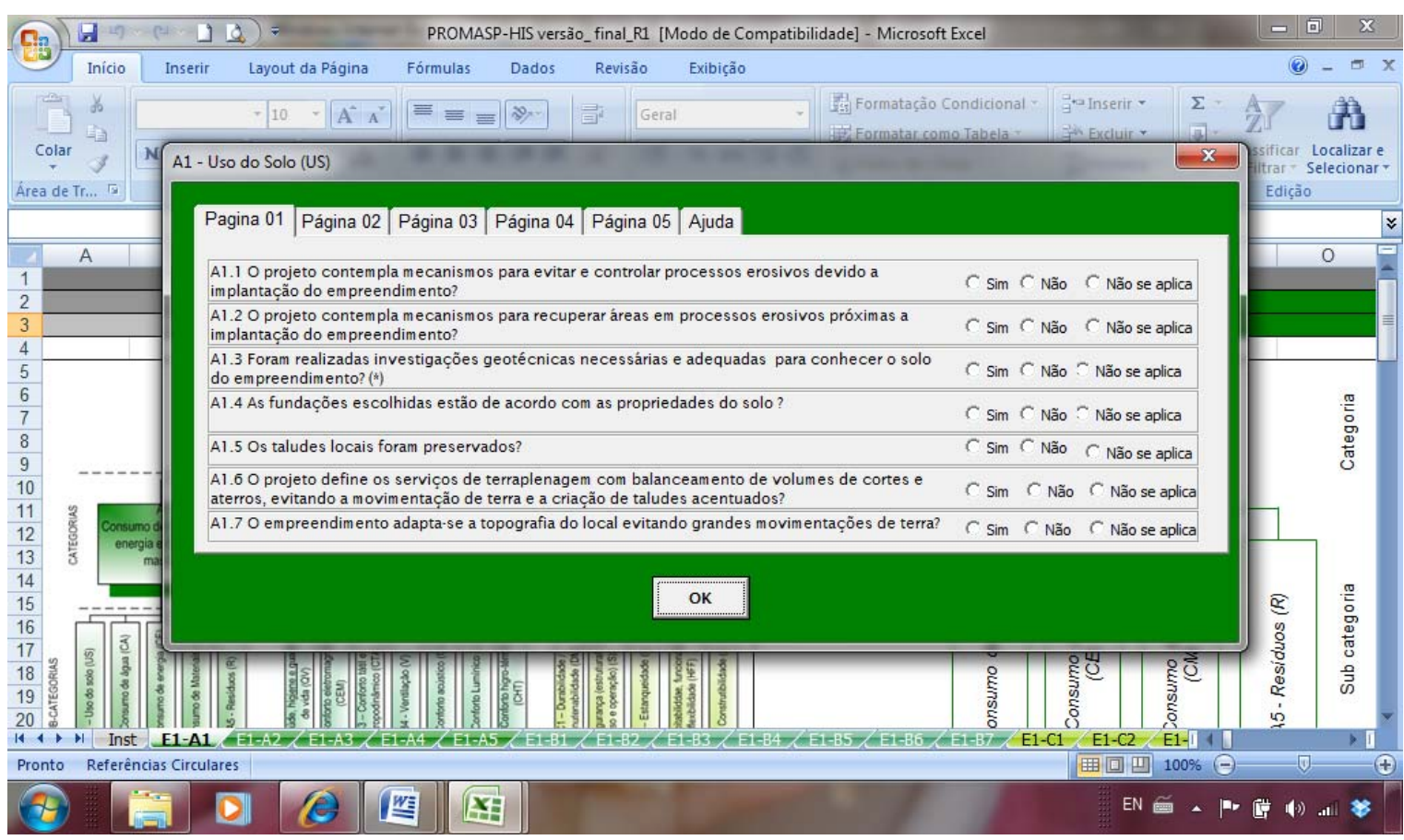

Figura 3 - Apresentação da tela do PROMASP-HIS, exemplificando a categoria A - Consumo de recursos energia e fluxo de massa e a subcategoria A1 - Uso do solo 


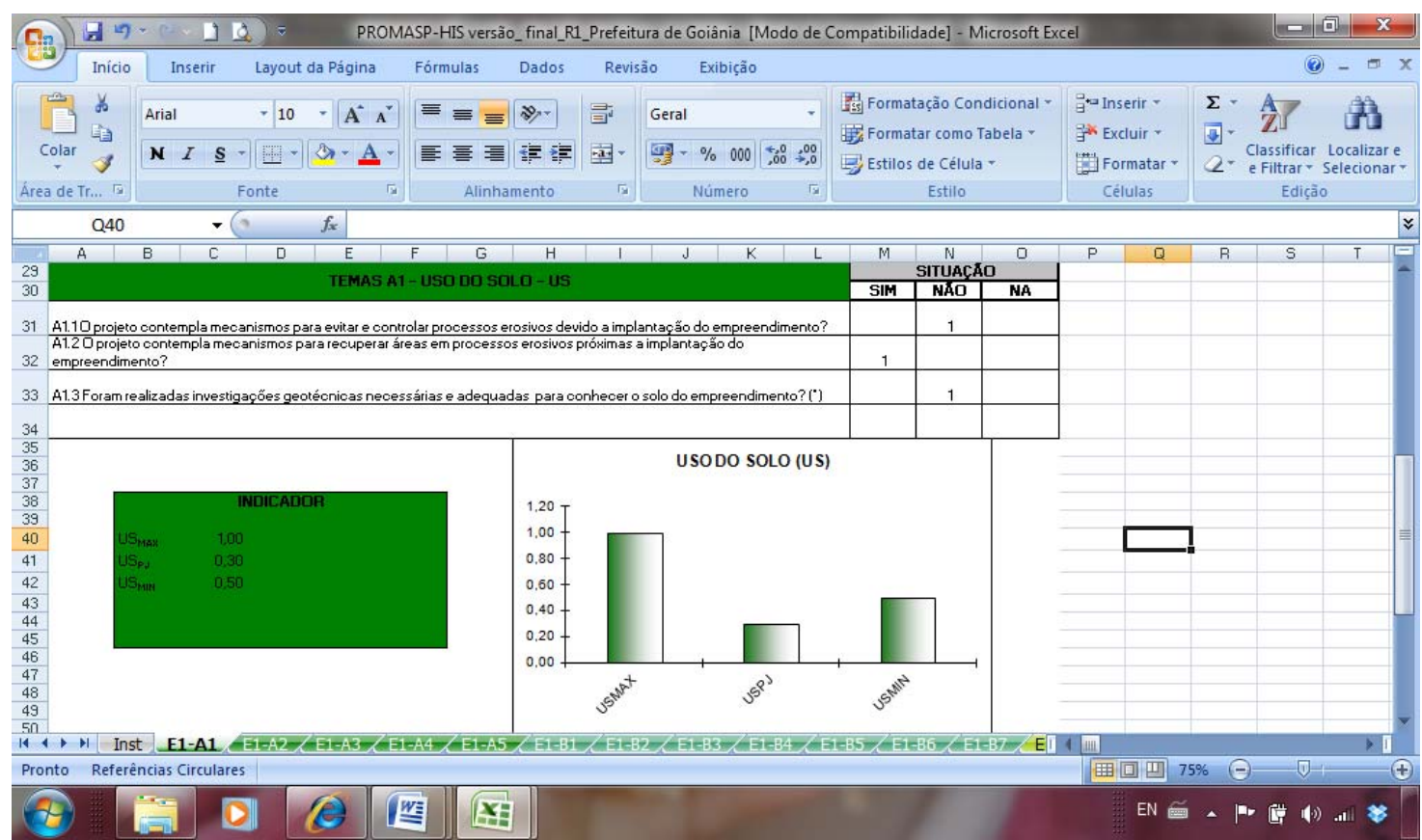

Figura 4 - Apresentação do indicador com seu respectivo índice em conjunto com o resultado gráfico da subcategoria A1 - Uso do solo

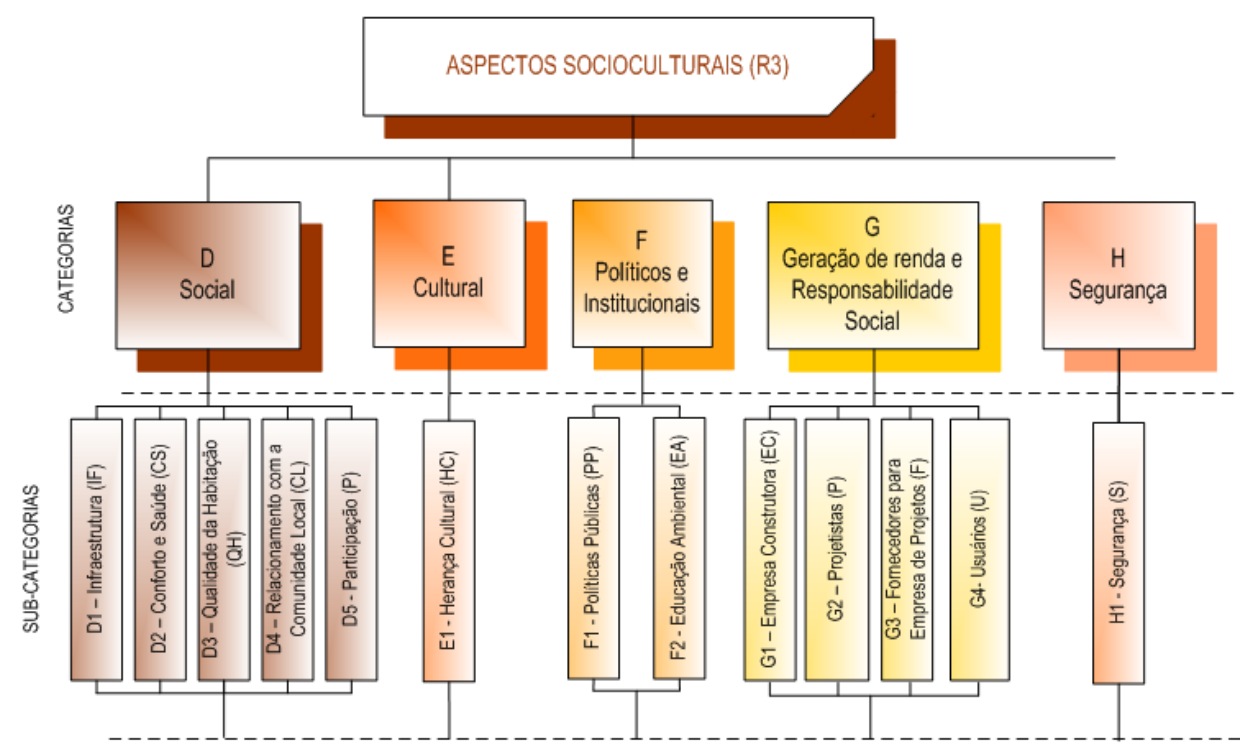

Figura 5 - Aspectos socioculturais para a análise dos projetos completos das edificações

\section{Aspectos socioculturais para a análise dos projetos completos}

Os aspectos socioculturais para a análise dos projetos completos foram divididos em cinco categorias (D, E, F, G e H), as quais, por sua vez, foram divididas em subcategorias, conforme pode ser observado na Figura 5. As subcategorias são os indicadores socioculturais para a análise dos projetos completos das edificações.

Os indicadores socioculturais (subcategorias dos aspectos socioculturais) para a análise dos projetos completos das edificações foram estabelecidos conforme o Quadro 2. O tratamento dado aos temas, indicadores e índices relacionados aos aspectos socioculturais é o mesmo daquele dado aos objetos correspondentes aos aspectos ambientais.

A título de exemplo, alguns dos temas propostos para a subcategoria HC - Herança cultural, que pertence à categoria $\mathrm{E}$ - Cultural, são apresentados na Figura 6. 
Quadro 2 - Indicadores socioculturais para a análise dos projetos completos das edificações, equação e quantidade de perguntas (temas) para cada indicador

\begin{tabular}{|c|c|c|c|}
\hline Categoria & $\begin{array}{l}\text { Subcategoria (indicador de sustentabilidade } \\
\text { sociocultural) }\end{array}$ & Equações & $\begin{array}{c}\text { Qtde de } \\
\text { temas }\end{array}$ \\
\hline \multirow{5}{*}{$\begin{array}{l}\text { (D) } \\
\text { Social }\end{array}$} & Infraestrutura (IF) & $I F=Q S / Q T$ & 11 \\
\hline & Conforto e saúde (CS) & $C S=Q S / Q T$ & 9 \\
\hline & Qualidade do produto/habitação (QP) & $Q P=Q S / Q T$ & 10 \\
\hline & Relacionamento com a comunidade local (CL) & $C L=Q S / Q T$ & 6 \\
\hline & Participação (P) & $P=Q S / Q T$ & 8 \\
\hline $\begin{array}{c}\text { (E) } \\
\text { Cultural }\end{array}$ & Herança cultural (HC) & $H C=Q S / Q T$ & 8 \\
\hline \multirow{2}{*}{$\begin{array}{c}\text { (F) } \\
\text { Político e } \\
\text { Institucional } \\
\end{array}$} & Políticas públicas (PP) & $P P=Q S / Q T$ & 18 \\
\hline & Educação ambiental (EA) & $E A=Q S / Q T$ & 3 \\
\hline \multirow{4}{*}{$\begin{array}{c}(\mathrm{G}) \\
\text { Geração de } \\
\text { Renda e } \\
\text { Responsabili- } \\
\text { dade Social } \\
\end{array}$} & Empresas construtoras (EC) & $E C=Q S / Q T$ & 31 \\
\hline & Empresas de projeto (EP) & $E P=Q S / Q T$ & 35 \\
\hline & Fornecedores para empresas de projeto $(\mathrm{F})$ & $F=Q S / Q T$ & 9 \\
\hline & Usuários (U) & $U=Q S / Q T$ & 3 \\
\hline $\begin{array}{c}(\mathrm{H}) \\
\text { Segurança }\end{array}$ & Segurança (S) & $S=Q S / Q T$ & 4 \\
\hline
\end{tabular}

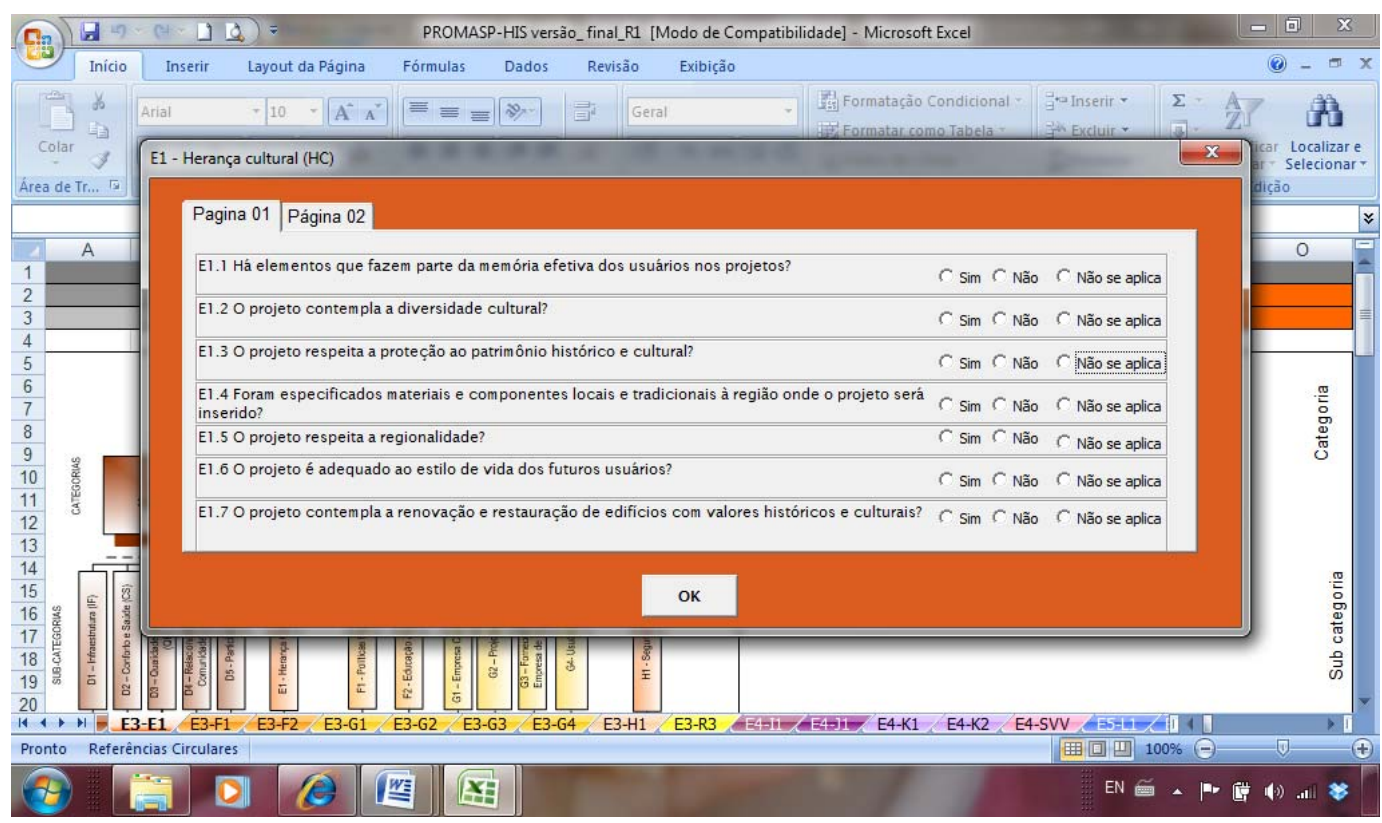

Figura 6 - Exemplos dos temas propostos para a subcategoria HC - Herança cultural, que pertence à categoria E - Cultural

\section{Aspectos econômicos para a análise dos projetos completos}

Os aspectos econômicos para a análise dos projetos completos foram estabelecidos em apenas uma categoria (L), a qual, por sua vez, foi dividida em subcategorias, conforme pode ser observado na Figura 7. As subcategorias são os indicadores econômicos para a análise dos projetos completos das edificações.
Os indicadores econômicos (subcategorias dos aspectos econômicos) para a análise dos projetos completos das edificações foram estabelecidos conforme o Quadro 3. O tratamento dado aos temas, indicadores e índices relacionados aos aspectos econômicos é o mesmo daquele dado aos objetos correspondentes aos aspectos ambientais e socioculturais.

Na Figura 8 é ilustrado o exemplo de aplicação dos temas propostos para a subcategoria C - Custo de construção, operação e manutenção. 


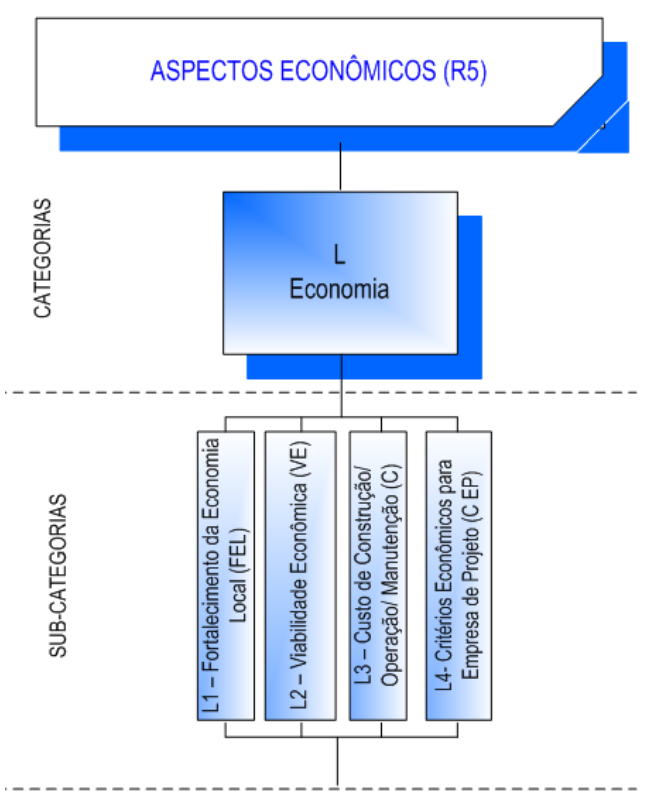

Figura 7 - Aspectos econômicos para a análise dos projetos completos das edificações

\begin{tabular}{|c|l|c|c|}
\hline Categoria & \multicolumn{1}{|c|}{$\begin{array}{c}\text { Subcategoria (indicadores econômicos para a análise } \\
\text { dos projetos completos das edificações) }\end{array}$} & Equações & $\begin{array}{c}\text { Qtde de } \\
\text { temas }\end{array}$ \\
\hline \multirow{3}{*}{$\begin{array}{c}\text { E) } \\
\text { Economia }\end{array}$} & Fortalecimento da economia local (FEL) & $F E L=Q S / Q T$ & 4 \\
\cline { 2 - 4 } & Viabilidade econômica (VE) & $V E=Q S / Q T$ & 5 \\
\cline { 2 - 4 } & Custo de construção, operação e manutenção (C) & $C=Q S / Q T$ & 7 \\
\cline { 2 - 4 } & Critérios econômicos para empresas de projeto (CEP) & $C E P=Q S / Q T$ & 3 \\
\hline
\end{tabular}

Quadro 3 - Indicadores econômicos para a análise dos projetos completos das edificações, equações e quantidade de perguntas (temas) para cada indicador

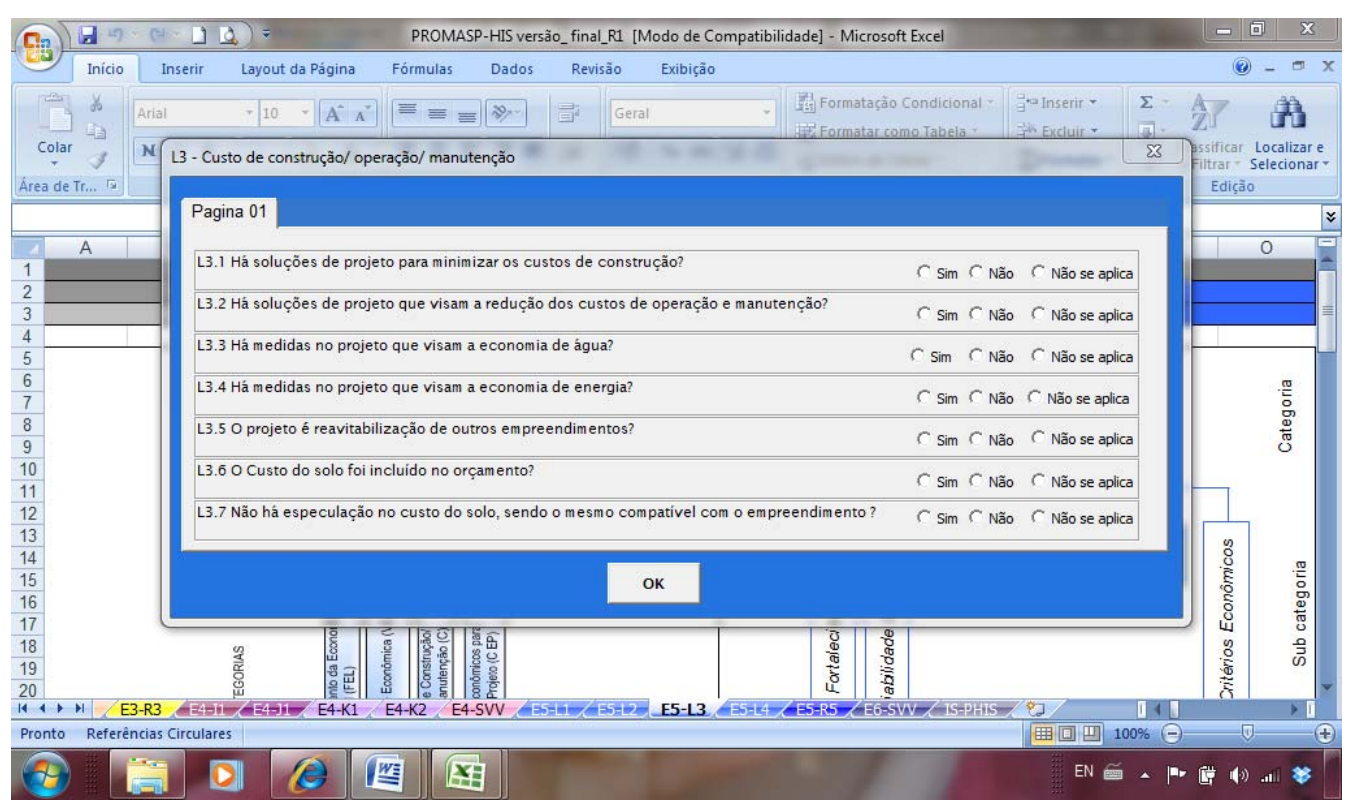

Figura 8 - Exemplos dos temas propostos para a subcategoria C - Custo de construção, operação e manutenção 


\section{Índice do projeto}

O índice de sustentabilidade do projeto é obtido pela média dos índices dos aspectos ambientais, socioculturais e econômicos. Com valores entre 0 e 100, considerou-se sustentável o valor médio igual ou superior a 50 .

\section{Aplicação da metodologia MASP-HIS e análise dos resultados}

A seguir, são descritos e detalhados dois projetos de habitações de interesse social desenvolvidos na região metropolitana de Goiânia, os quais foram usados para a verificação da eficácia da metodologia MASP-HIS e da própria ferramenta PROMASP-HIS. Posteriormente, são apresentados e analisados os resultados referentes aos indicadores e índices de sustentabilidade dos referidos projetos.

\section{Projeto-padrão de habitações de interesse social da prefeitura de Goiânia}

Este projeto, denominado de Projeto 1 (Figura 9), é um projeto-padrão de habitações de interesse social unifamiliares pertencentes à prefeitura da cidade de Goiânia, para a população de baixa renda da região metropolitana daquela cidade. As características gerais do projeto são:

(a) unidades habitacionais dispostas em terrenos de propriedade da prefeitura;

(b) inflexibilidade, de modo que o projeto não mude em função das características climáticas, de relevo e de orientação geográfica;

(c) unidades habitacionais com 40,80 $\mathrm{m}^{2}$ de área construída;

(d) terreno de cada unidade sem tamanho definido e dependente de cada conjunto habitacional; e

(e) unidade com quatro cômodos - uma sala e cozinha, dois quartos e um banheiro, além de uma área de circulação (hall).

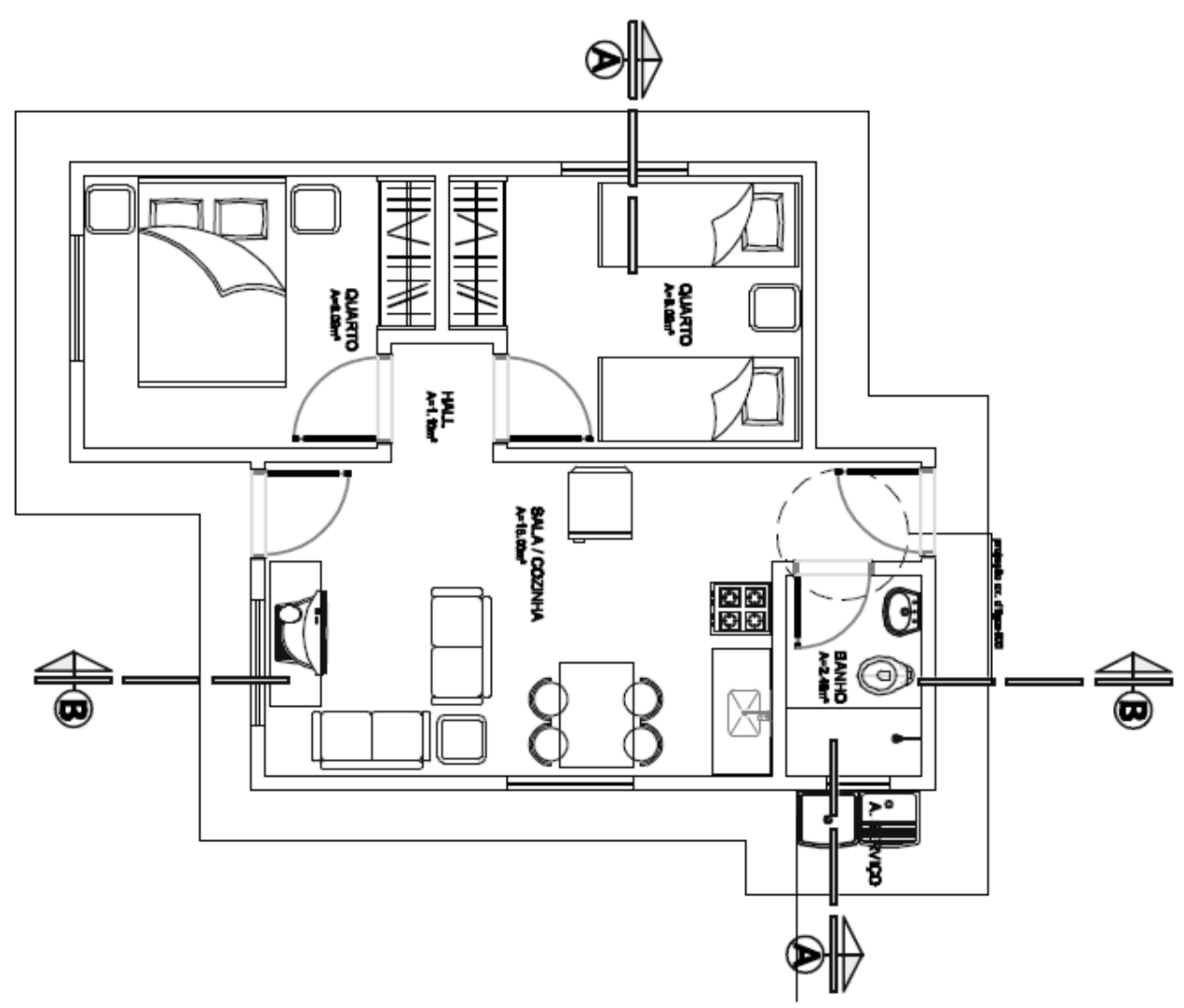

Figura 9 - Planta baixa do Projeto 1 


\section{Projeto-padrão de habitações de interesse social da organização não governamental Habitat Brasil}

Este projeto, denominado de Projeto 2 (Figura 10), é um projeto-padrão de habitações de interesse social unifamiliares pertencentes à organização não governamental Habitat Brasil, para a população de baixa renda da região metropolitana de Goiânia. As características gerais do projeto são:

(a) unidades habitacionais dispostas em terrenos públicos;

(b) inflexibilidade, de modo que o projeto não mude em função das características climáticas, de relevo e de orientação geográfica; (c) unidades habitacionais com $50 \mathrm{~m}^{2}$ de área construída;

(d) terreno de cada unidade sem tamanho definido e dependente de cada conjunto habitacional; e

(e) unidade com seis cômodos - uma sala, uma cozinha, dois quartos, um banheiro e uma área de serviço, além de uma área de circulação (hall).

\section{Análises dos resultados}

\section{Aspectos ambientais}

Os índices parciais de sustentabilidade referentes aos aspectos ambientais dos projetos completos estão apresentados na Tabela 1, a qual proporciona a análise comparativa entre os resultados dos Projetos 1 e 2. Na Figura 11, tem-se a visualização gráfica dos índices ambientais, por categoria.

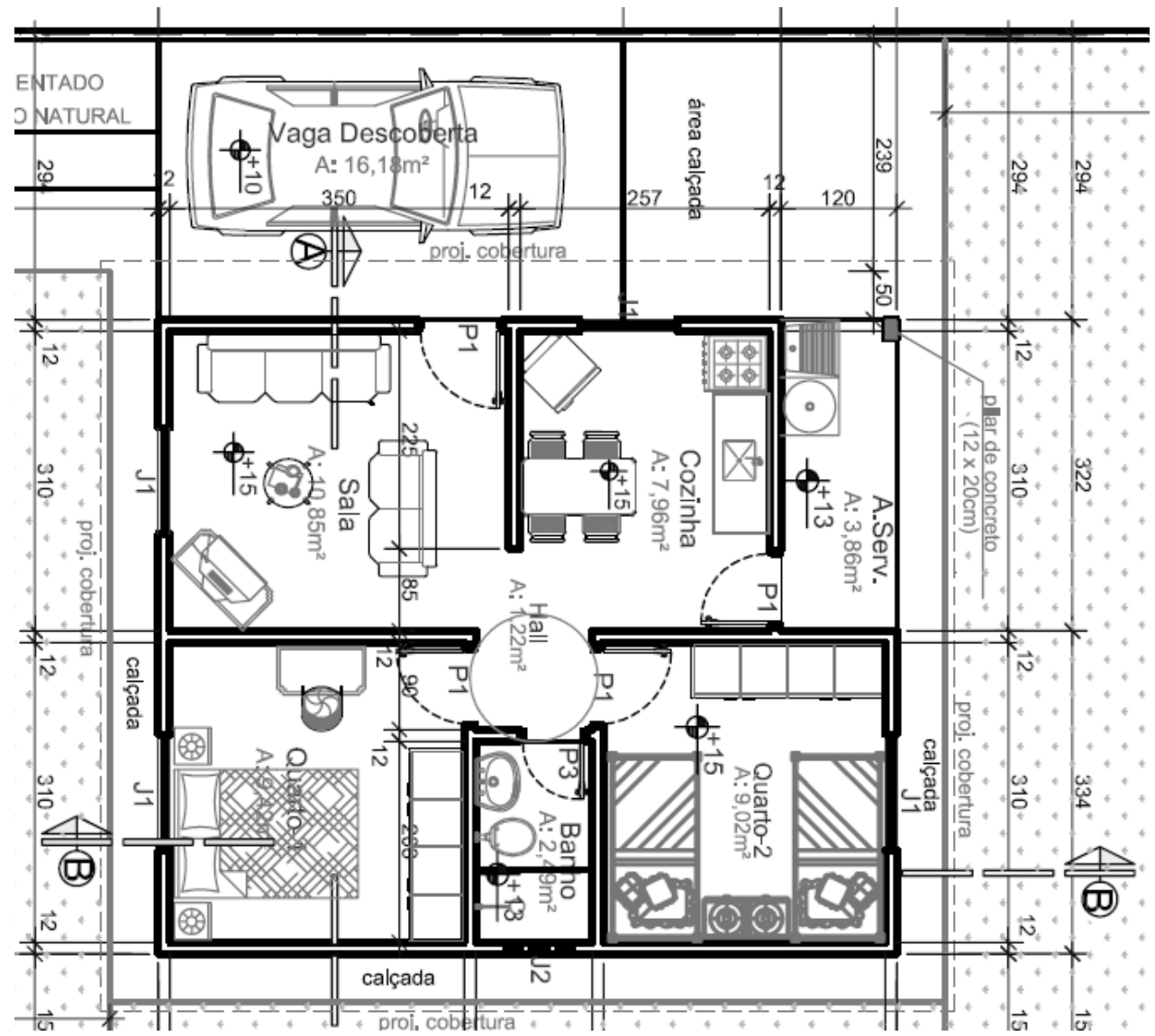

Figura 10 - Planta baixa do Projeto 2 
Tabela 1 - Aspectos ambientais dos projetos completos

\begin{tabular}{l|c|c}
\hline \multicolumn{1}{c|}{ ASPECTOS AMBIENTAIS } & PROJETO 1 & PROJETO 2 \\
\cline { 2 - 3 } \multicolumn{1}{c}{ de massa } & $\mathbf{2 0 , 7 7}$ & $\mathbf{1 8 , 2 7}$ \\
\hline Categoria A: Consumo de recursos - energia e fluxo & $\mathbf{2 4 , 3 8}$ & $\mathbf{2 1 , 8 5}$ \\
\hline Subcategoria: Uso do solo (US) & 29,63 & 25,00 \\
Subcategoria: Consumo de água (CA) & 18,18 & 18,18 \\
Subcategoria: Consumo de energia (CE) & 42,86 & 28,57 \\
Subcategoria: Consumo de materiais (CM) & 31,25 & 37,50 \\
Subcategoria: Resíduos (R) & 00,00 & 00,00 \\
\hline \multicolumn{1}{c}{ Categoria B: Qualidade interna da habitação - } & & \\
& $\mathbf{2 2 , 4 3}$ & $\mathbf{2 2 , 0 8}$ \\
\hline Subcategoria: Saúde, higiene e qualidade de vida (QV) & 37,50 & 37,50 \\
Subcategoria: Conforto eletromagnético (CEM) & 00,00 & 00,00 \\
Subcategoria: Conforto tátil e antropodinâmico (CTA) & 5,56 & 5,56 \\
Subcategoria: Ventilação (V) & 27,27 & 18,18 \\
Subcategoria: Conforto acústico (CAC) & 00,00 & 00,00 \\
Subcategoria: Conforto lumínico (CL) & 60,00 & 66,67 \\
Subcategoria: Conforto higrotérmico (CHT) & 26,67 & 26,67 \\
\hline \multicolumn{1}{c}{ Categoria C: Qualidade do produto/habitação } & $\mathbf{1 5 , 5 0}$ & $\mathbf{1 0 , 9 0}$ \\
\hline Subcategoria: Durabilidade/Manutenabilidade (DM) & 00,00 & 00,00 \\
Subcategoria: Segurança (S) & 10,00 & 9,52 \\
Subcategoria: Estanqueidade (E) & 30,00 & 20,00 \\
Subcategoria: Habitabilidade, funcionabilidade, & & \\
flexibilidade (HFF) & 37,50 & 25,00 \\
Subcategoria: Construtibilidade (C) & 00,00 & 00,00 \\
\hline
\end{tabular}

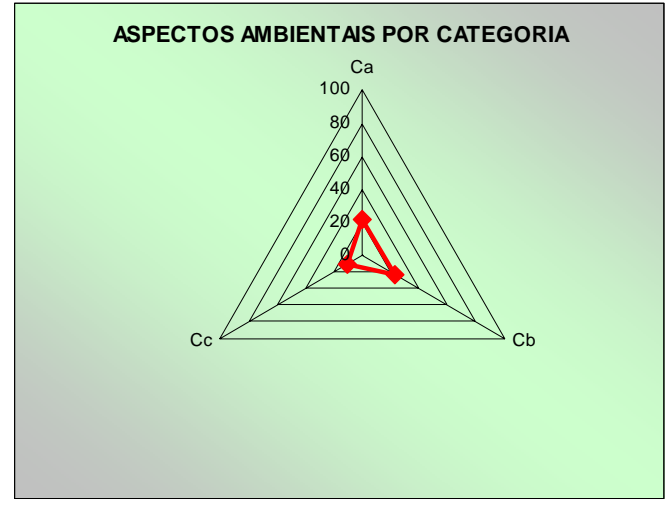

(a) Projeto 1

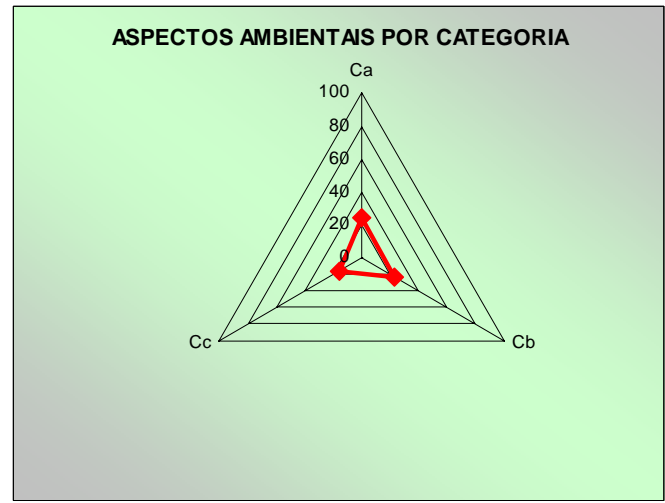

(b) Projeto 2

Figura 11 - Índices dos aspectos ambientais dos projetos completos, por categoria

De acordo com os resultados da Tabela 2, os dois projetos têm seus índices de sustentabilidade relativos aos aspectos ambientais próximos entre si e muito baixos. Na escala de 0 a 100, seus índices são 20,77 e 18,27 respectivamente para os Projetos 1 e 2. Conclui-se, portanto, que ambos têm pouca preocupação com os aspectos ambientais de construção sustentável, notadamente no que se refere aos seguintes indicadores:
(a) consumo de água;
(b) resíduos;
(c) conforto eletromagnético;

(d) conforto tátil e antropodinâmico;

(e) ventilação (Projeto 2);

(f) conforto acústico;

(g) durabilidade/manutenabilidade;

(h) segurança; e

(i) construtibilidade.

Nota-se, por outro lado, que os indicadores com sustentabilidade mais elevada foram:

(a) consumo de energia (Projeto 1); 
(b) consumo de materiais (Projeto 2);

(c) saúde, higiene e qualidade de vida;

(d) conforto lumínico; e

(e) habitabilidade, funcionabilidade e flexibilidade.

O conforto lumínico, para ambos os projetos, foi o indicador que apresentou o melhor desempenho, sendo o único a alcançar o valor mínimo $(60,00$ e 66,67 respectivamente para os Projetos 1 e 2) estabelecido para classificar as ações como sustentáveis.

\section{Aspectos socioculturais}

Os índices parciais de sustentabilidade referentes aos aspectos socioculturais dos projetos completos estão apresentados na Tabela 2, a qual proporciona a análise comparativa entre os resultados dos Projetos 1 e 2. Na Figura 12 tem-se a visualização gráfica dos índices socioculturais, por categoria.

Em relação aos resultados da Tabela 2, novamente os dois projetos apresentaram índices de sustentabilidade relativos aos aspectos socioculturais muito baixos. Na escala de 0 a 100 , seus índices são 26,69 e 34,22 respectivamente para os Projetos 1 e 2. Verifica-se que o Projeto 2 é mais sustentável nesse quesito, mas os dois têm pouca preocupação com os aspectos socioculturais. Os indicadores socioculturais com menor índice de sustentabilidade foram:
(a) herança cultural;
(b) educação ambiental (Projeto 1);
(c) empresa construtora (Projeto 1);
(d) usuários (Projeto 1); e
(e) segurança.
Os indicadores socioculturais com os maiores índices foram:
(a) qualidade da habitação;
(b) relacionamento com a comunidade local
(Projeto 2);
(c) políticas públicas;
(d) fornecedores para empresa de projetos; e
(e) usuários (Projeto 2).

Tabela 2 - Aspectos socioculturais dos projetos completos

\begin{tabular}{|c|c|c|}
\hline \multirow{2}{*}{ ASPECTOS SOCIOCULTURAIS } & PROJETO 1 & PROJETO 2 \\
\hline & 26,69 & 34,22 \\
\hline Categoria D: Social & 31,94 & 36,54 \\
\hline Subcategoria: Infraestrutura (IF) & 30,00 & 36,36 \\
\hline Subcategoria: Conforto e saúde (CS) & 36,36 & 36,36 \\
\hline Subcategoria: Qualidade da habitação $(\mathrm{CH})$ & 60,00 & 60,00 \\
\hline Subcategoria: Relacionamento com a comunidade & & \\
\hline local (CL) & 33,33 & 50,00 \\
\hline Subcategoria: Participação (P) & 00,00 & 00,00 \\
\hline Categoria E: Cultural & 16,67 & 16,67 \\
\hline Subcategoria: Herança cultural (HC) & 16,67 & 16,67 \\
\hline Categoria F: Políticas e institucionais & 27,78 & 47,21 \\
\hline Subcategoria: Políticas públicas (PP) & 55,56 & 61,11 \\
\hline Subcategoria: Educação ambiental (EA) & 00,00 & 33,33 \\
\hline $\begin{array}{c}\text { Categoria G: Geração de renda e } \\
\text { responsabilidade social }\end{array}$ & 32,05 & 45,65 \\
\hline Subcategoria: Empresa construtora (EC) & 17,78 & 38,10 \\
\hline Subcategoria: Projetista (P) & 43,75 & 24,49 \\
\hline Subcategoria: Fornecedores para empresa de & & \\
\hline $\begin{array}{l}\text { projetos (F) } \\
\text { Subcategoria: Usuários (U) }\end{array}$ & $\begin{array}{l}66,67 \\
00,00\end{array}$ & $\begin{array}{l}60,00 \\
60,00\end{array}$ \\
\hline Categoria H: Segurança & 25,00 & 25,00 \\
\hline Subcategoria: Segurança (S) & 0,25 & 0,25 \\
\hline
\end{tabular}




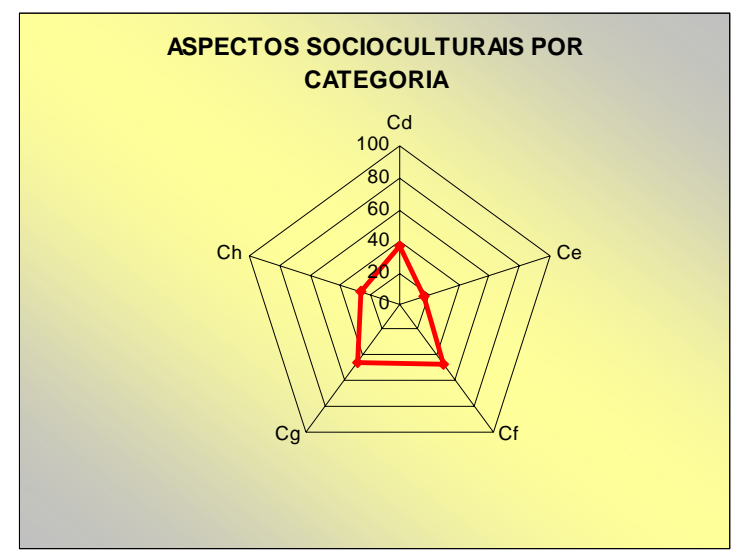

(a) Projeto 1

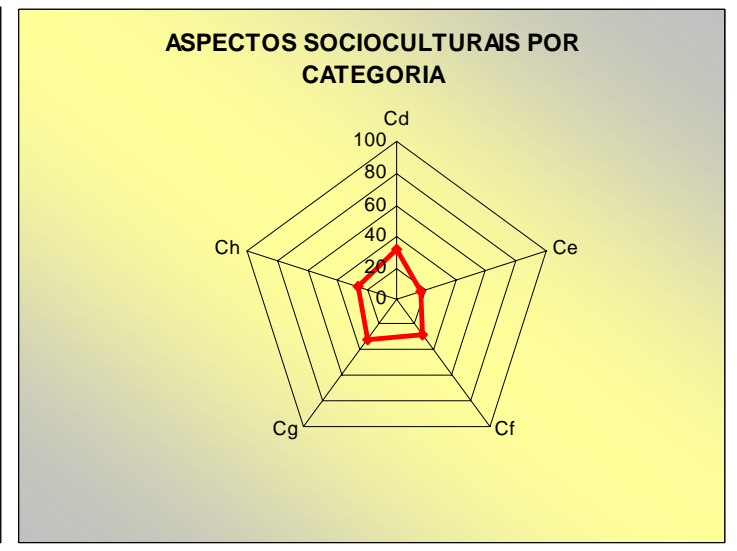

(b) Projeto 2

Figura 12 - Índices dos aspectos socioculturais dos projetos completos, por categorias

Tabela 3 - Aspectos econômicos dos projetos completos

\begin{tabular}{l|c|c}
\multicolumn{1}{c|}{ ASPECTOS ECONÔMICOS } & PROJETO 1 & PROJETO 2 \\
\cline { 2 - 3 } & $\mathbf{2 8 , 8 1}$ & $\mathbf{2 2 , 5 0}$ \\
\hline \multicolumn{1}{|c|}{ Categoria L Econômica } & $\mathbf{2 8 , 8 1}$ & $\mathbf{2 2 , 5 0}$ \\
\hline Subcategoria: Fortalecimento da economia local (FEL) & 33,33 & 33,33 \\
\hline Subcategoria: Viabilidade econômica (VE) & 20,00 & 40,00 \\
\hline Subcategoria: Custo de construção/operação/manutenção (C) & 28,57 & 16,67 \\
\hline Subcategoria: Critérios econômicos para empresa de projeto (CEP) & 33,33 & 00,00 \\
\hline
\end{tabular}

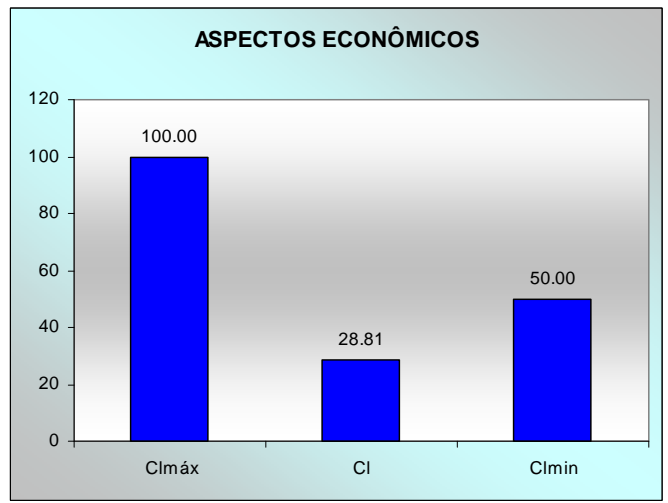

(a) Projeto 1

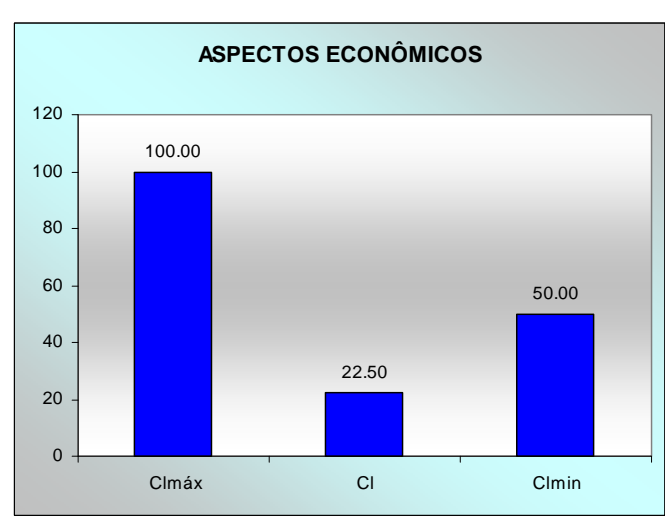

(b) Projeto 2

Figura 13 - Aspectos econômicos dos projetos completos, por categoria

\section{Aspectos econômicos}

Os índices parciais de sustentabilidade referentes aos aspectos econômicos dos projetos completos estão apresentados na Tabela 3, a qual proporciona a análise comparativa entre os resultados dos projetos 1 e 2. Na Figura 13 tem-se a visualização gráfica dos índices dos aspectos econômicos, por categoria.

Segundo os resultados da Tabela 3, os dois projetos têm seus índices de sustentabilidade relativos aos aspectos econômicos dos projetos completos novamente muito baixos. Na escala de 0 a 100, seus índices são respectivamente 28,81 e 22,50 para os Projetos 1 e 2 . O projeto 1 é mais sustentável nesse quesito, mas ambos têm pouca preocupação com os aspectos econômicos de construção sustentável, especialmente em relação aos seguintes indicadores:
(a) viabilidade econômica (Projeto 1);
(b) custo de construção/operação/manutenção
(Projeto 2); e
(c) critérios econômicos para empresa de projeto (Projeto 2).

Os indicadores econômicos mais sustentáveis são: 
(a) fortalecimento da economia local;

(b) viabilidade econômica (Projeto 2); e

(c) critérios econômicos para empresa de projeto (Projeto 1).

\section{Índice de Sustentabilidade de Projeto}

Como consequência dos índices de sustentabilidade parciais, relativos aos aspectos ambientais, socioculturais e econômicos, os índices de sustentabilidade de projeto para os Projetos 1 e 2 são respectivamente 25,42 e 24,99.

\section{Considerações finais}

A metodologia MASP-HIS tem grande potencial para a verificação da sustentabilidade de projetos de habitações de interesse social, uma vez que contempla os aspectos ambiental, sociocultural e econômico, em um contexto que engloba indicadores de sustentabilidade a partir de critérios e requisitos consagrados e aceitos mundialmente.

Além de possibilitar a inclusão de outros critérios e requisitos que podem surgir no decorrer do tempo, é possível acrescentar, além dos 361 temas, outros que se enquadram às subcategorias propostas. Essas inserções podem ser feitas com o uso das mesmas formulações apresentadas neste trabalho.

A inovação da metodologia MASP-HIS consiste em apresentar em um único índice resultados referentes aos aspectos ambientais, socioculturais e econômicos, o que possibilita a identificação de possíveis melhorias nos projetos visando ao aumento desse índice.

A ferramenta PROMASP-HIS, criada para analisar a sustentabilidade de projetos conforme os preceitos conceituais da metodologia que a originou, é de fácil utilização e permite que novos indicadores (subcategorias) e temas propostos sejam ampliados e/ou alterados, de acordo com as necessidades específicas de projeto ou com a própria evolução dos materiais e métodos construtivos.

A metodologia foi aplicada em dois projetos (Projetos 1 e 2), selecionados por estar sendo utilizados em programas habitacionais de interesse social na região de Goiânia.

Após a aplicação da metodologia MASP-HIS, concluiu-se que os Projetos 1 e 2 não podem ser considerados sustentáveis, uma vez que os índices de sustentabilidade de projeto de ambos ficaram em torno de 25, numa escala de 0 a 100 .

Apesar de os dois projetos terem seus índices de sustentabilidade muito próximos, observa-se que essa proximidade ocorre após o equacionamento dos índices parciais das várias categorias envolvidas, os quais são, na maioria das vezes, diferentes entre os projetos, conforme as Tabelas 1,2 e 3 . Assim, é necessário que se faça uma análise criteriosa de todos os índices parciais, de maneira a encontrar e solucionar pontos críticos do projeto, para a elevação de seus respectivos índices de sustentabilidade.

Como sugestões para futuros estudos, apontam-se a análise da viabilidade de estabelecimento de diferentes pesos para as categorias e subcategorias consideradas e a validação da metodologia MASPHIS proposta.

\section{Referências bibliográficas}

AGOPYAN, V. et al. Alternativas Para Redução de Desperdício de Materiais nos Canteiros de Obra: relatório final. São Paulo: Epusp, 1998.

ASSOCIAÇÃO BRASILEIRA DE NORMAS TÉCNICAS. NBR 15575: desempenho de edifícios habitacionais de até cinco pavimentos. Rio de Janeiro, 2010.

AQUA. Edifícios do Setor de Serviços: escritórios e edifícios escolares. In: AQUA. Referencial

Técnico de Certificação. São Paulo: Fundação Vanzolini, 2007.

BRAGANÇA, L.; MATHEUS, R. A Report on Sustainable Building and Construction in Portugal. In: WORLD SUSTAINABLE BUILDING CONFERENCE, 8., Melbourne, 2008. Proceedings... Melbourne, 2008.

BRASIL. Lei 10.295, de 17 de outubro de 2001, que dispõe sobre eficiência energética. Brasília, DF. Disponível em: <www.planalto.gov.br>.

Acesso em: 15 nov. 2011.

BUILDING RESEARCH ESTABLISHMENT. BREEAM Fact File: versão 3. 2007. Disponível em:

$<$ http://www.breeam.org/filelibrary/Breeam_Fact_ File_Version_3_February_2007.pdf >. Acesso em: 6 out. 2011.

BUREAU/ENSEIGNEMENT Guide Pratique Du Referentiel Pour la Qualite Environmentale des Bâtiments. 2008. Disponível em:

$<$ http://pt.scribd.com/doc/25757672/GuidePratique-BureauEnseignement-Decembre-2008>. Acesso em: 10 mar. 2012.

CHEUNG, K.; CHENG, V. Designing for Sustainability of Building: Hong Kong context. In: WORLD SUSTAINABLE BUILDING CONFERENCE, 8., Melbourne, 2008.

Proceedings... Melbourne, 2008. 
CHOGUILL, C. L. The Search for Policies to Support Sustainable Housing. Habitat International, v. 31, n. 1, p. 143-149, 2007.

COLE, R. J. et al. Building Environmental Assessment Tools: current and future roles. In: WORLD SUSTAINABLE BUILDING CONFERENCE 2005, Tokyo, 2005.

Proceedings... Tokyo, 2005.

\section{CONSELHO NACIONAL DO MEIO}

AMBIENTE. Resolução n. ${ }^{\circ}$ 307, de 5 de julho de 2002. Brasília. Disponível em:

$<$ http://www.conama.gov.br>. Acesso em: 5 fev. 2012.

\section{CONSTRUCTION INDUSTRY RESEARCH} AND INFORMATION ASSOCIATION.

Sustainable Construction: company indicators. London: CIRIA/WS Atkins Consultants, 2001. (CIRIA's Project RP609).

CRISP NETWORK. Construction-Related Sustainability Indicators. CRISP newsletter, v. 1, 2011.

DESMYTER, J.; HUOVILA, P. Performance Indicators For Health Comfort and Safety of the Indoor Environment. In: WORLD

SUSTAINABLE BUILDING CONFERENCE, 8., Melbourne, 2008. Proceedings... Melbourne, 2008.

ETHOS. Indicadores Ethos de Responsabilidade Social. Disponível em: <http://www.ethos.org.br>. Acesso em: 12 ago. 2011.

FOSSATI, M. Metodologia Para Avaliação da Sustentabilidade de Projetos de Edifícios: o caso de escritórios em Florianópolis. Florianópolis, 2008. Tese (Doutorado) - Escola de Engenharia, Universidade Federal de Santa Catarina, Florianópolis, 2008.

GIBBERD, J. The Sustainable Building Assessment Tool: integration sustainability into current design and building processes. In: WORLD SUSTAINABLE BUILDING CONFERENCE, 8., Melbourne, 2008. Proceedings... Melbourne, 2008.

HUOVILA, P. Framework and Indication For Sustainable Urban Development. In: WORLD SUSTAINABLE BUILDING CONFERENCE, 8., Melbourne, 2008. Proceedings... Melbourne, 2008.

INTERNATIONAL ORGANIZATION FOR STANDARDIZATION. ISO/TS 21929-1: sustainability in building construction. Sustainability indicators: parte 1: framework for the development of indicators for building. Swiss, 2006a.
IWAMURA, K. The Movement Towards Sustainable Building in Japan. In: WGBC CONGRESS, San Francisco, 2005. Proceedings... San Francisco, 2005.

KAATZ, E. et al. Advancing Key Outcomes of Sustainability Building Assessment. Building Research and Information, v. 34, n. 4, p. 308320, 2006.

KRIGSVOLL, G. Life Cycle Costing as Part of Decision Making Use of Building Information Models. In: WORLD SUSTAINABLE BUILDING CONFERENCE, 8., Melbourne, 2008. Proceedings... Melbourne, 2008.

LAM, K. K. A Report on the State of Sustainable Building in Hong Kong. In: WORLD

SUSTAINABLE BUILDING CONFERENCE, 8., Melbourne, 2008. Proceedings... Melbourne, 2008.

LARSSON, N. An Overview of the GBC Method and GBTool. 2005. Disponível em: <http://www.greenbuilding.ca/down/gbc2005/GBt ool_2k5_Demo_unlocked/>. Acesso em: 15 ago. 2008.

LÜTZKENDORF, T.; ILOMÄKI, A. How to Assess the Contribution of Building to Sustainable Development. In: BMBF FORUM FOR SUSTAINABILY, 4., Bremen, 2007.

Proceedings... Bremen: German EU Council Presidency, 2007.

OLIVEIRA, D. P. Contribuição Para a Avaliação Ambiental de Subsistemas de Cobertura em Habitações de Interesse Social. 192 f. Porto Alegre, 2005. Dissertação (Mestrado em Engenharia Civil) - Escala de Engenharia, Universidade Federal do Rio Grande do Sul, Porto Alegre, 2005.

ORGANIZATION FOR ECONOMIC COOPERATION AND DEVELOPMENT. OECD Core Set of Indicators for Environmental Performance Reviews: a synthesis report by the group on the state of the environment. Paris: OECD, 1993. 39 p. Environment Monographs, n. 83.

SILVA, V. G. Avaliação da Sustentabilidade de Edifícios de Escritórios Brasileiros: diretrizes e bases metodológicas. Tese (Doutorado) - Escola Politécnica, Universidade de São Paulo, São Paulo, 2003.

SILVA, V. G. Indicadores de Sustentabilidade de Edifícios Estado da Arte e Desafios Para o Desenvolvimento no Brasil. Ambiente Construído, Porto Alegre, v. 7, n. 1, p. 47-66, jan./mar. 2007. 
SPERB, M. Avaliação de Tipologias

Habitacionais a Partir da Caracterização de Impactos Ambientais Relacionados a Materiais de Construção. 149 f. Porto Alegre, 2000.

Dissertação (Mestrado em Engenharia Civil) Escola de Engenharia, Universidade Federal do Rio Grande do Sul, Porto Alegre, 2000.
UNITED STATES GREEN BUILDING COUCIL. An Introduction to the U. S. Green Building Council and the LEED Green Building Rating System. Washington, DC. Disponível em: <www.usgbc.org>. Acesso em: 15 ago. 2011.

WALLBAUM, H. Sustainability Indicators for the Built Environment: the challenges ahead. In: WORLD SUSTAINABLE BUILDING CONFERENCE, 8., Melbourne, 2008.

Proceedings... Melbourne, 2008.

Revista Ambiente Construído

Associação Nacional de Tecnologia do Ambiente Construído

Av. Osvaldo Aranha, 99 - 3o andar, Centro

Porto Alegre - RS - Brasil

CEP $90035-190$

Telefone: +55 (51) 3308-4084

Fax: +55 (51) 3308-4054

www. seer. ufrgs. br/ ambienteconstruido

E-mail: ambienteconstruido@ufrgs.br 